20th International Congress on Modelling and Simulation, Adelaide, Australia, 1-6 December 2013

www.mssanz.org.au/modsim2013

\title{
Intraday Volatility Forecast in Australian Equity Market
}

\author{
Abhay K Singh, David E Allen and Robert J Powell \\ Edith Cowan University, Perth, Western Australia \\ Email: a.singh@ecu.edu.au
}

\begin{abstract}
On the afternoon of May 6, 2010 Dow Jones Industrial Average (DJIA) plunged about 1000 points (about $9 \%$ ) in a matter of minutes before rebounding almost as quickly. This was the biggest one day point decline on an intraday basis in the DJIA's history. An almost similar dramatic change in intraday volatility was observed on April 4, 2000 when DJIA dropped by 4.8\%. These historical events present very compelling argument for the need of robust econometrics models which can forecast intraday asset volatility. There are numerous models available in the finance literature to model financial asset volatility. Various Autoregressive Conditional Heteroskedastic (ARCH) time series models are widely used for modelling daily (end of day) volatility of the financial assets. The family of basic GARCH models work well for modelling daily volatility but they are proven to be not as efficient for intraday volatility. The last two decades has seen some research augmenting the GARCH family of models to forecast intraday volatility, the Multiplicative Component GARCH (MCGARCH) model of Engle \& Sokalska (2012) is the most recent of them. MCGARCH models the conditional variance as the multiplicative product of daily, diurnal, and stochastic intraday volatility of the financial asset. In this paper we use MCGARCH model to forecast intraday volatility of Australia's S\&P/ASX-50 stock market, we also use the model to forecast the intraday Value at Risk. As the model requires a daily volatility component, we test a GARCH based estimate and a Realized Variance based estimate of daily volatility component.
\end{abstract}

Keywords: Intraday returns, volatility, value at risk, $A R C H$, realized variance 
A. Singh, D. Allen and R. Powell, Intraday Volatility Forecast in Australian Equity Market

\section{INTRODUCTION}

The last decade and a half has seen stock trading transitioning from the frequency of daily transactions to a higher frequency. This change has occurred due to the ease of availability of tick by tick stock prices or so called high frequency data sets. There are groups of active high frequency market traders worldwide in the major financial markets. These traders need intraday updates of the market risk associated with the instruments for effective trading regimes.

As seen during the Global Financial Crisis of 2007-2009 market volatility can change very dramatically in a matter of days. This dramatic change in market volatility is not just seen on a daily level but also happens on an intraday level as noticed in the so called Flash Crashes of DJIA (2010 and 2004). The evidence of sudden price changes in the stock market and growth in the number of high frequency trading requires market risk modelling and forecasting for intraday periods. Efficient intraday modelling of risk can provide a better guard against the sudden price changes and hence can prevent major losses.

$\mathrm{VaR}$ is the most widely used market risk measure in financial risk management and it is also used by practitioners such as porfolio managers to account for future market risk. VaR forecasting at an intraday level requires modelling and forecasting intraday returns. There has been an increase in models which are developed for intraday returns by augmenting the ARCH-GARCH family of models, Andersen and Bollerslev (1997, 1998 and 1999), Giot (2000, 2005), Dacorogna, Gencay, Muller, Olsen, and Pictet (2001), Muller, Dacorogna, and Pictet (1996), Engle and Gallo (2006). Engle \& Sokalska (2012) is the most recent study which develops a new MCGARCH model by building on Andersen and Bollerslev(1997,1998). MCGARCH model decomposes the volatility of high-frequency asset returns into multiplicative components, which are easy to estimate and interpret.

Although limited in numbers but there are previous studies about forecasting intraday VAR. These studies have either used conventional ARCH-GARCH approaches or their variants. Giot(2005),Coroneo and Veredas(2006), Dionne et al.(2009) and the most recently So and Xu (2013).

This paper presents the first application (to the best of our knowledge) of the recently developed MCGARCH model to forecast intraday VaR of ASX-50 stock exchange. The empirical study also analyse the effectiveness of the intraday VaR forecasts for different intraday intervals using backtests. Our research significantly contributes to the literature as it is based on 1,5 and 10 minute regularly spaced intraday return series compared to the earlier studies which mostly used 10, 15 or 30 minutes returns to forecast $\mathrm{VaR}$ for that period.

The rest of the paper is organized as follows . Section 2 briefly outlines the model. Section 3 describes the data and methodology. This is followed by major results in section 4 and finally conclusion in section 5 .

\section{MCGARCH MODEL}

This section gives a brief introduction to the MCGARCH model. See Engle and Sokalska (2012) for a comprehensive discussion of the model.

MCGARCH model is a variant of a GARCH model for intraday financial assets' returns. The conditional variance of a high frequency return time series is considered to be the multiplicative product of three components; the daily, diurnal and stochastic intraday volatility. Consider the conditional compounded return series, $R_{t, i}$ for an asset $A$, where $t$ is any particular day and $i$ is the regularly spaced intraday time period. According to MCGARCH the intraday return process of $R_{t, i}$ can be described by the following process $^{1}$ :

$$
R_{t, i}=\sqrt{h_{t} s_{i} q_{t, i}} \varepsilon_{t, i} \text { and } \varepsilon_{t, i} \sim N(0,1)
$$

where

$h_{t}$ is the daily variance component

${ }^{1}$ We have used the similar notations in the equations as in Engle and Sokalska (2012) for a better understanding of the original study. 
$s_{i}$ is the diurnal (calendar) variance component in each intraday period

$q_{t, i}$ is the intraday variance component

$\varepsilon_{t, i}$ is an error term.

Engle and Sokalska (2012) used commercially available daily volatility forecasts for the daily variance component in their empirical analysis. It is also possible to forecast the daily variance component using GARCH models (Andersen and Bollerslev, 1997; 1998). The daily variance component can also be calculated using the realized volatility estimates (Engle and Gallo, 2006). In this study we use the daily variance forecasts of ASX-50 obtained from a GARCH model with student-t distribution ${ }^{2}$.

The diurnal component is estimated as the variance of intraday returns in each regularly spaced intraday time period.

$$
\begin{gathered}
\frac{R_{t, i}^{2}}{h_{t}}=s_{i} q_{t, i} \varepsilon_{t, i}^{2} \\
s_{i}=\frac{1}{T} \sum_{t=1}^{T} \frac{R_{t, i}^{2}}{h_{t}}
\end{gathered}
$$

The stochastic intraday variance component $q_{t, i}$ is then modelled as a GARH (p,q) process after normalizing the returns by daily and diurnal variance.

$$
\begin{gathered}
z_{t, i}=R_{t, i} / \sqrt{h_{i} s_{i}}=\sqrt{q_{t, i}} \varepsilon_{t, i}, \\
q_{t, i}=\omega+\alpha\left(R_{t, i-1} / \sqrt{h_{t} s_{i-1}}\right)^{2}+\beta q_{t, i-1}
\end{gathered}
$$

Although several GARCH(p,q) specifications can be tested, in this empirical exercise we use GARCH $(1,1)$ specification empirical exercise as it is the most popular GARCH specification.

\section{Data \& Methodology}

Our dataset in this analysis is obtained from Thomson Reuters Tick History's high frequency database. We use regularly spaced intraday prices on 1, 5 and 10 minutes interval of ASX-50 stock market for a period of 3 months from 4-Jan-2012 to 31-Mar-2012. This gives 62 days of intraday logarithmic returns for fitting the model and forecasting. As we are using GARCH based forecasts for the daily component in the MCGARCH model we also use daily returns for ASX-50 for a period of 04-Feb-2004 to 31-Mar-2012 (2062 days).

Daily standard deviation forecasts for the daily component in the MCGARCH model are obtained using student-t GARCH $(1,1)^{3}$ model. We use a moving window of 2000 daily returns to forecast 62 days of daily standard deviation (4-Jan-2012 to 31-Mar-2012). The model is refitted every 5 moving days.

For the VaR forecasts intraday data is divided into 52 estimation and 10 forecasting days. R software with rugarch package is used for the computation.

We now discuss the major results.

\section{Discussion of the Results}

In this section we discuss the major results obtained from $1 \mathrm{~min}, 5 \mathrm{~min}$ and $10 \mathrm{~min}$ intraday data. Although various GARCH specifications can be tested but for this analysis we keep the same setup for all the intraday time periods to check the applicability of a uniform model over various intraday time intervals. The intraday returns are restricted to the trading hours for ASX-50, which is 10:00:00 AM to 4:00:00 PM

\footnotetext{
${ }^{2} \mathrm{~A}$ more comprehensive version of the paper will also test the Realized Volatility based daily variance

${ }^{3}$ We use student-t GARCH $(1,1)$ here to account for skewness in the data. Other GARCH models can also be tested in future research.
} 
(Australian Eastern Standard Time). Also the first return of the day (or the overnight return) has been deleted from the time series which is a common practice in empirical analysis of intraday returns. We first present the results for the 1 minute intraday returns.

Figure-1 shows the timeseries plot of the daily forecasted variance obtained from GARCH $(1,1)$ with student-t innovations. These forecasts are used in the MCGARCH model as the daily volatility component for all the three intraday intervals.

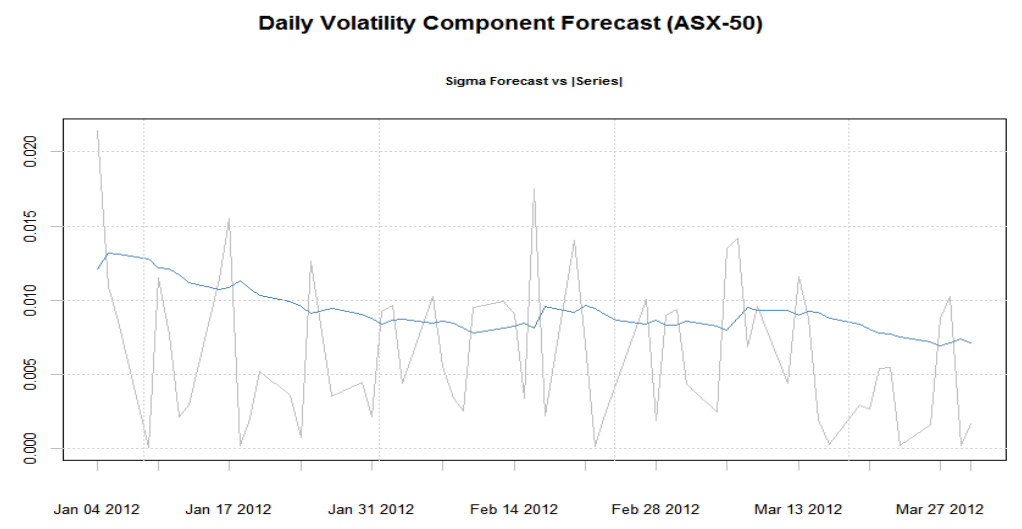

Figure 1: Daily Volatility Forecast (Jan 2012 to Mar 2012)

In the first part of our empirical exercise we evaluate the MCGARCH model on the complete $1 \mathrm{~min}$ intraday dataset. Figure- 2 below shows the five timeseries plots, the top level plot gives the logarithmic intraday returns, the plots below gives the Diurnal, Daily and Intraday Volatility components obtained from the model. The fifth plot at the bottom of figure-2 gives the total composite volatility for the intraday data obtained by combining the three volatility components. The parameters estimated from the model are reported in table-1. All the parameters in Table-1 are significant and hence we move onto the VaR forecasts.

Table 1: Intraday GARCH results for ASX-50 (1 Min Returns)

\begin{tabular}{|l|l|l|l|l|}
\hline Parameter & Value & Standard error & T Statistics & P-Value \\
\hline \hline$\omega$ & 0.132037 & 0.017805 & 7.4158 & 0 \\
\hline$\alpha$ & 0.066031 & 0.005654 & 11.6797 & 0 \\
\hline$\beta$ & 0.899526 & 0.009213 & 97.6407 & 0 \\
\hline
\end{tabular}



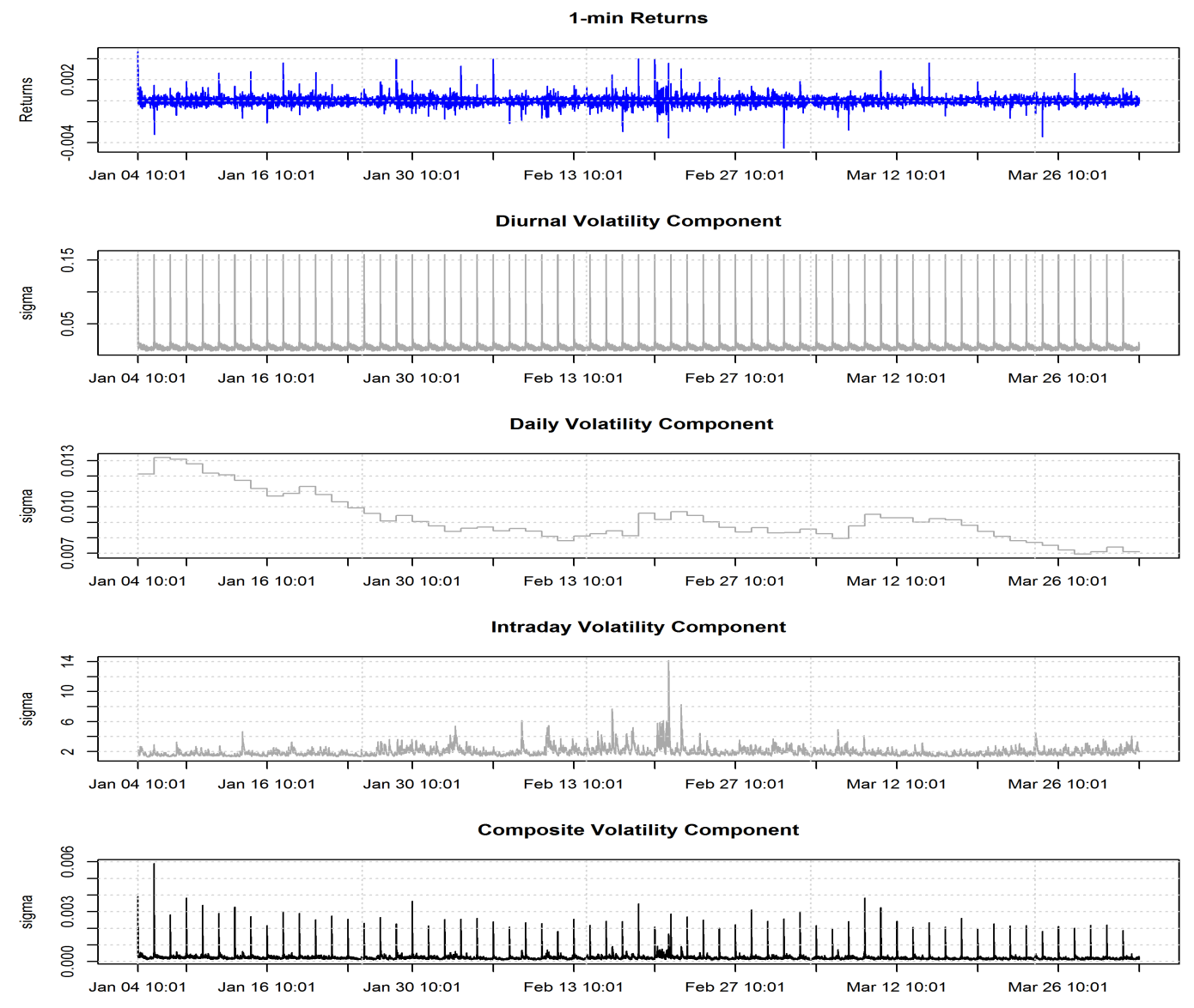

Figure 2: Volatility Components for ASX-50 (1 Min Returns)

\section{Intraday VaR Forecast}

In this part of the analysis use the MCGARCH model to forecast $1 \%$ VaR. A moving window of 10 days is chosen, which is estimated after each day or 360 intraday returns for 1-minute interval, 72 for 5-minutes and 36 for 10 minutes. The intraday data is divided in 52 days for estimating the model and 10 days for testing the forecasting ability of the model. We obtain 3600, 720 and $360 \mathrm{VaR}$ forecasts for the $1 \mathrm{~min}, 5 \mathrm{~min}$ and $10 \mathrm{~min}$ intraday data respectively. These intraday forecasts are evaluated against the actual intraday returns using Unconditional (Kupiec) and Conditional (Christoffersen) Coverage tests.

Table-2 below gives the backtest results for the intraday VaR forecasts in all the intraday intervals. The results clearly show that MCGARCH fits well to the changing dynamics of the intraday stock market and provides VaR forecasts with valid number of violations. Figure-3 plots the VaR forecasts for all the three intraday time periods. In all the three VaR forecast plots the spikes in the VaR observed can be accounted to the seasonal component around the opening of the trading day. 
A. Singh, D. Allen and R. Powell, Intraday Volatility Forecast in Australian Equity Market

Table 2: Intraday-VaR Back-Test Results

\begin{tabular}{|c|c|c|c|c|c|c|c|c|c|c|c|}
\hline \multicolumn{4}{|c|}{ Forecasts and Outcomes } & \multicolumn{4}{|c|}{ Unconditional Coverage Test } & \multicolumn{4}{|c|}{ Conditional Coverage Test } \\
\hline & $\begin{array}{l}\text { Expected } \\
\text { Ex- } \\
\text { ceedances }\end{array}$ & $\begin{array}{l}\text { Actual Ex- } \\
\text { ceedances }\end{array}$ & $\begin{array}{l}\text { Null } \\
\text { Hypothesis } \\
\text { (H0) }\end{array}$ & $\begin{array}{l}\text { Likelihood } \\
\text { Ratio }\end{array}$ & Critical Value & P-Value* & Decision & $\begin{array}{l}\text { Likelihood } \\
\text { Ratio }\end{array}$ & Critical Value & P-Value* & Decision \\
\hline \multicolumn{12}{|c|}{1 Min Intraday VaR } \\
\hline $1 \%$ VaR & 36 & 40 & $\begin{array}{l}\text { Correct Ex- } \\
\text { ceedances }\end{array}$ & 0.433 & 3.841 & 0.51 & Fail to Reject $\mathrm{H} 0$ & 0.96 & 5.991 & 0.619 & Fail to Reject $\mathrm{H} 0$ \\
\hline \multicolumn{12}{|c|}{5 Min Intraday VaR } \\
\hline $1 \% \mathrm{VaR}$ & 7.2 & 10 & $\begin{array}{l}\text { Correct Ex- } \\
\text { ceedances }\end{array}$ & 0.981 & 3.841 & 0.322 & Fail to Reject H0 & 1.263 & 5.991 & 0.532 & Fail to Reject $\mathrm{H} 0$ \\
\hline \multicolumn{12}{|c|}{10 Min Intraday VaR } \\
\hline $1 \% \mathrm{VaR}$ & 3.6 & 3 & $\begin{array}{l}\text { Correct Ex- } \\
\text { ceedances }\end{array}$ & 0.107 & 3.841 & 0.743 & Fail to Reject $\mathrm{H} 0$ & 0.158 & 5.991 & 0.924 & Fail to Reject $\mathrm{H} 0$ \\
\hline
\end{tabular}

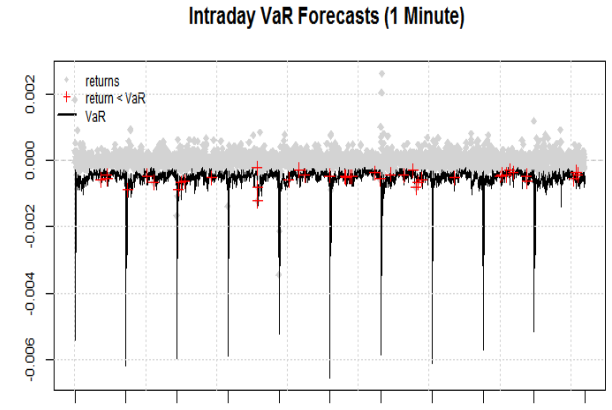

Mar 19 10:01 Mar 21 10:01 Mar 23 10:01 Mar 27 10:01 Mar 29 10:01 Mar 30 16:00

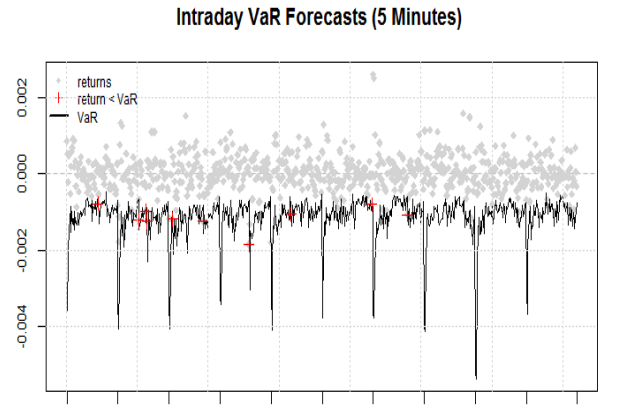

Mar 19 10:05 Mar 21 10:05 Mar 23 10:05 Mar 27 10:05 Mar 29 10:05 Mar 30 16:00

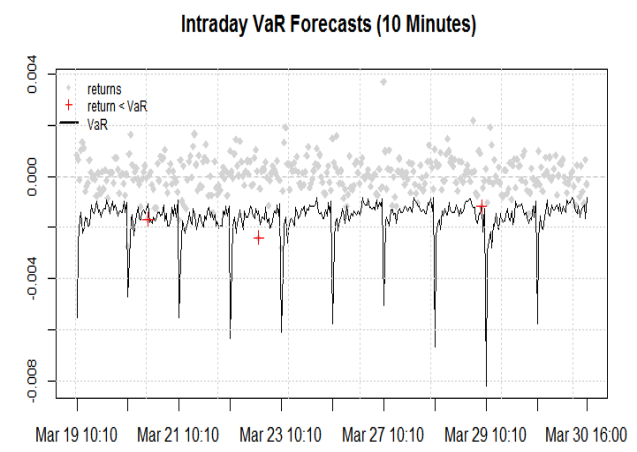

Figure 3: Intraday VaR Forecasts vs Actual Returns

\section{Conclusion}

In this paper, we used the recently developed MCGARCH model for intraday price data to model and evaluate intraday VaR. We analysed the performance of the model for three high frequency intraday intervals of 1 minute, 5 minutes and 10 minutes. The results suggests that the MCGARCH model fits 
well to the high frequency intraday returns. The performance of the model to forecast VaR also suggests that it fits well to the changing dynamics of the intraday stock prices. Although the model is implemented only on one intraday return series, it has been tested for three equally spaced time periods including 1 minute and 5 minutes period. The overall performance of the model to forecast the intraday volatility shows that the MCGARCH model can be useful for forecasting intraday VaR. The analysis in this paper also provides ground work for future research to enhance the performance of intraday VaR forecasts.

The main limitation is the use of single asset's return series, application of this model to a high frequency portfolio or various assets will become a part of a more comprehensive study. The MCGARCH model can also be evaluated using realized volatility estimates which will be the subject of future research.

\section{ACKNOWLEDGMENTS}

The first author would like to acknowledge the financial support of Edith Cowan University's Early Career Research grant. The authors also acknowledge the funding support of the ARC

\section{REFERENCES}

Andersen, T. G., \& Bollerslev, T. (1997). Intraday periodicity and volatility persistence in financial markets. Journal of Empirical Finance, 4.

Andersen, T. G., \& Bollerslev, T. (1998). Deutsche mark dollar volatility: Intraday activity patterns, macroeconomic announcements, and longer run dependencies. Journal of Finance, 53(1), 219-265.

Andersen, T. G., \& Bollerslev, T. (1998).Forecasting financial market volatility: sample frequency vis- 'avis forecast horizon. Journal of Empirical Finance, 6.

Christoffersen, P. (1998). Evaluating Interval Forecasts. International Economic Review, 39, 841-862.

Christoffersen, P., Hahn, J. and Inoue, A. (2001). Testing and Comparing Value-at-Risk Measures. Journal of Empirical Finance, 8, 325-342.

Coroneo, L., \& Veredas, D. (2006). Intradaily seasonality of returns distribution. A quantile regression approach and intradaily VaR estimation.CORE Discussion Papers, 2006077

Dacorogna, M., Gencay. R, Muller U., Olsen, R. \& Pictet, O. (2001). An introduction to high-frequency finance: Academic Press.

Dionne, G., Duchesne, P., \& Pacurar, M. (2009). Intraday Value at Risk (IVaR) using tick-by-tick data with application to the Toronto stock exchange.Journal of Empirical Finance, 16, 777-792.

Engle, R. F., \& Gallo, G. M. (2006). A multiple indicators model for volatility using intra-daily data. Journal of Econometrics, 131(1-2), 3-27.

Engle, R. F., \& Sokalska, M. E. (2012). Forecasting intraday volatility in the US equity market. Multiplicative component GARCH. Journal of Financial Econometrics, 10(1), 54-83.

Giot, P. (2005). Market risk models for intraday data. The European Journal of Finance, 11(4), 309-324.

Giot, P. (2005). Time transformations, intraday data and volatility models. Journal of Computational Finance, 4, 31-62.

Muller, U., Dacorogna, M., \& Pictet, O. (1996). Heavy tails in high-frequency financial data: Olsen preprint.

So, M. P., \& Xu, R. (2013). Forecasting Intraday Volatility and Value-at-Risk with High-Frequency Data. Asia-Pacific Financial Markets, 20(1), 83-111 